\title{
ANALISIS FAKTOR - FAKTOR YANG MEMPENGARUHI LOYALITAS KONSUMEN TEH CAP BANDULAN DI KABUPATEN PEKALONGAN
}

\author{
ANALYSIS OF FACTORS AFFECTING LOYALTY OF “CAP \\ BANDULAN" TEA CONSUMERS IN PEKALONGAN REGENCY
}

\author{
Safira Dwi Hanggraeni, Kustopo Budiraharjo, Siswanto Imam Santoso \\ Program Studi Agribisnis \\ Fakultas Peternakan dan Pertanian, Universitas Diponegoro \\ Email: safiradwih@gmail.com
}

\begin{abstract}
Consumer loyalty is a positive characteristic of consumers towards a brand which is characterized by the use of certain products for a long period of time or making regular repeat purchases. This study was conducted to analyze the level of consumer loyalty of "Cap Bandulan" Tea products and what factors influence consumer loyalty to "Cap Bandulan" Tea products in Pekalongan Regency. The research was conducted in July - August 2020 in selected sub-districts, namely Kedungwuni, Wonopringgo, Karangdadap, Bojong, and Doro in Pekalongan Regency. The research method used is a survey method using a questionnaire. Sampling was carried out using accidental sampling method where the researcher met by chance or incidentally with respondents with a total sample of 100 people. The methods used in data collection are interviews and observation. The data analysis method using a loyalty pyramid and multiple linear regression analysis. The results of the analysis of the loyalty pyramid are quite good with the biggest level of consumer loyalty of the "Cap Bandulan" Tea due to the liking factor of the product brand (liking the brand) which is equal to 57\%. The results of multiple linear regression analysis explain that consumer satisfaction and brand image partially influence consumer loyalty, while product quality and product prices do not partially influence consumer loyalty of Cap Bandulan Tea. Consumer satisfaction, brand image, product quality and product prices simultaneously affect consumer loyalty of Bandulan Tea by $46.5 \%$.
\end{abstract}

Keyword: Customer satisfaction, Brand image, Product quality, product price, Loyalty pyramid, Consumer loyalty.

\begin{abstract}
ABSTRAK
Loyalitas konsumen merupakan sifat positif dari konsumen terhadap suatu merek yang ditandai dengan penggunaan produk tertentu dalam jangka waktu yang panjang atau melakukan pembelian berulang secara teratur. Penelitian ini dilakukan untuk menganalisis tingkatan loyalitas konsumen produk Teh Cap Bandulan serta faktor-faktor apa saja yang mempengaruhi loyalitas konsumen terhadap produk Teh Cap Bandulan di Kabupaten Pekalongan. Penelitian dilakukan pada bulan Juli - Agustus 2020 di beberapa kecamatan terpilih yaitu Kedungwuni, Wonopringgo, Karangdadap, Bojong, dan Doro di Kabupaten
\end{abstract}


Pekalongan. Metode penelitian yang digunakan adalah metode survei menggunakan kuesioner. Pengambilan sampel dilakukan menggunakan metode accidental sampling dimana peneliti bertemu secara kebetulan atau insidental dengan responden dengan jumlah sampel sebanyak 100 orang. Metode yang digunakan dalam pengambilan data adalah wawancara dan observasi. Metode analisis data dilakukan menggunakan piramida loyalitas dan analisis regresi linear berganda. Hasil analisis piramida loyalitas sudah cukup baik dengan tingkatan loyalitas konsumen Teh Cap Bandulan terbesar dikarenakan faktor kesukaan terhadap merek produk (liking the brand) yaitu sebesar 57\%. Hasil analisis regresi linear berganda menerangkan bahwa kepuasan konsumen dan citra merek berpengaruh secara parsial terhadap loyalitas konsumen sedangkan kualitas produk dan harga produk tidak berpengaruh secara parsial terhadap loyalitas konsumen Teh Cap Bandulan. Kepuasan konsumen, citra merek, kualitas produk dan harga produk secara simultan mempengaruhi loyalitas konsumen Teh Cap Bandulan sebesar $46,5 \%$.

Kata Kunci : kepuasan konsumen, citra merek, kualitas produk, harga produk, piramida loyalitas, loyalitas konsumen.

\section{PENDAHULUAN}

Teh merupakan salah satu minuman yang biasa dikonsumsi oleh masyarakat Indonesia dalam kehidupan sehari-hari. Terdapat berbagai macam varian teh meliputi teh putih, teh hijau, teh hitam, teh oolong, teh kuning, dan teh pu erh. Keenam macam varian teh tersebut berasal dari tanaman teh yang sama namun yang menjadikannya berbeda adalah cara dalam memproses teh tersebut yaitu pada tingkatan proses oksidasi yang dilakukan setelah melalui tahap panen (Somantri dan Tanti, 2013).

Teh Cap Bandulan merupakan salah satu produk teh yang masih bertahan hingga sekarang. Teh Cap Bandulan yang diproduksi oleh CV. Budi Djaya Pekalongan telah berdiri sejak tahun 1933. Produk teh Cap Bandulan ini telah dipasarkan hampir di seluruh kota di Pulau Jawa, Bali serta Pulau Kalimantan. CV. Budi Djaya dulunya hanyalah industri rumah tangga, namun kini produknya telah dikenal oleh mayoritas masyarakat di Indonesia. CV. Budi Djaya berhasil mengembangkan inovasinya yakni memunculkan berbagai macam produk teh dengan berbagai kemasan yang salah satunya adalah teh dalam kemasan cup gelas yang siap minum pada tahun 2008 dan teh dalam kemasan botol pada tahun 2009.

Meski telah berhasil memasarkan produknya ke berbagai daerah, hal ini tidak dapat menjamin bahwa Teh Cap Bandulan akan terus diminati oleh konsumennya. Ada beberapa kompetitor produk teh yang beredar di pasaran antara lain Teh Jawa, Teh Cap Poci, Teh Wangi Dandang, Teh Tong Tji, Teh 2Tang, dan beberapa merk lainnya. Persaingan produk teh yang sangat ketat di Indonesia menjadikan CV. Budi Djaya selaku pemegang merk Teh Cap Bandulan harus mampu mengetahui apa saja faktor - faktor yang dapat menjadikan konsumen bertahan dengan produk Teh Cap Bandulan. Loyalitas itu sendiri merupakan salah satu perilaku konsumen yang diharapkan terus ada bagi suatu 
perusahaan dikarenakan loyalitas berarti seorang konsumen atau pelanggan akan terus melakukan pembelian secara berkala terhadap produk dari perusahaan tersebut. Meningkatkan loyalitas konsumen sangat penting dilakukan oleh perusahaan supaya perusahaan dapat memenangkan persaingan bisnis yang sengit dan ketat tersebut. CV. Budi Djaya telah terbukti mampu membangun loyalitas dengan konsumennya, dibuktikan dengan produknya yang masih bisa bertahan hingga saat ini ditengah banyaknya produk teh dengan merk lain yang beredar di pasaran.

Caruana (2002) menyatakan bahwa loyalitas konsumen dapat dilihat dari penggunaan suatu produk tertentu secara terus-menerus yang dilakukan di masa mendatang. Faktor-faktor yang mempengaruhi loyalitas konsumen antara lain adalah harga, merek, promosi yang dilakukan perusahaan, serta kualitas dari produk itu sendiri (Dharmmesta, 1999). Konsumen yang merasakan kepuasan terhadap pelayanan dari perusahaan karena pelayanannya sesuai dengan kebutuhan dan harapan konsumen sebagai pelanggan juga merupakan faktor penting yang mempengaruhi loyalitas konsumen sebagai pelanggan dalam mengkonsumsi suatu produk (Larasati dan Suryaputra, 2013). Apabila perusahaan teh lain memiliki inovasi yang mampu menarik konsumen dapat menjadi ancaman karena memungkinan pelanggan yang sudah loyal pada suatu produk beralih ke produk lain yang dianggap lebih menarik karena berbagai inovasi yang ditawarkan. Penjelasan dan pengukuran loyalitas yaitu dari perilaku pelanggan yang memiliki frekuensi tinggi dalam melakukan pembelian produk dan sikap pelanggan yang mengacu pada komponen sikap seperti niat, perasaan, serta keyakinan untuk melakukan pembelian suatu produk (Buttle, 2004).

\section{METODE PENELITIAN}

Objek dalam penelitian ini adalah kepuasan konsumen, citra merek, kualitas produk dan harga produk terhadap loyalitas konsumen Teh Cap Bandulan di Kabupaten Pekalongan. Metode penelitian yang digunakan adalah metode survei menggunakan kuesioner. Metode survei merupakan metode penelitian yang dilakukan dari pengumpulan data menggunakan kuesioner sebagai alat yang disebarkan kepada sekelompok orang (West dan Turner, 2008). Tujuan dari digunakannya metode survei adalah untuk mendapatkan gambaran yang mewakili suatu daerah tertentu dengan benar. Metode yang digunakan untuk pengambilan sampel yaitu dengan metode accidental sampling dimana peneliti bertemu secara kebetulan atau insidental dengan responden yang cocok sebagai sumber penelitian (Etikan dan Bala, 2017). Teknik yang digunakan untuk penentuan jumlah sampel adalah kuota sampling. Pengambilan sampel dilakukan dengan memberikan jatah atau quorum tertentu terhadap suatu kelompok (Payadnya dan Jayantika, 2018). Sedangkan sampel yang digunakan dalam penelitian ini adalah sebanyak 100 responden. Peneliti mengambil 5 kecamatan secara acak yaitu Kecamatan Kedungwuni, Kecamatan Karangdadap, Kecamatan Bojong, Kecamatan Wonopringgo, dan Kecamatan Doro dimana setiap kecamatan diberikan jatah sebanyak 20 responden sehingga totalnya sejumlah 100 responden. 
Metode yang digunakan dalam pengambilan data adalah wawancara dan observasi. Data yang digunakan dalam penelitian ini merupakan data primer dan data sekunder. Data primer dalam penelitian ini didapatkan dari hasil observasi secara langsung dengan responden yang sesuai kriteria penelitian dan melakukan wawancara menggunakan pedoman kuesioner penelitian dengan responden yang ditemui secara tidak sengaja di toko ataupun swalayan yang menjual produk Teh Cap Bandulan, sedangkan data sekunder didapat dari instansi-instansi dan literatur yang berkaitan dengan penelitian ini meliputi buku, jurnal, dan penelitian terdahulu.

Pengolahan data dibantu oleh Ms. Excel dan SPSS 16.0. Analisis data dilakukan menggunakan analisis regresi linear berganda dan piramida loyalitas. Adapun rumus regresi sistematikanya sebagai berikut:

$Y=a+b_{1} X_{1}+b_{2} X_{2}+b_{3} X_{3}+b_{4} X_{4}+b_{5} X_{5}+e$

Dimana :

$\mathrm{Y}=$ Loyalitas konsumen

a $\quad=$ Konstanta

$\mathrm{b}_{1}-\mathrm{b}_{5}=$ Koefisien regresi variabel independen

$\mathrm{X}_{1} \quad=$ Kepuasan konsumen

$\mathrm{X}_{2} \quad=$ Kualitas servis

$\mathrm{X}_{3} \quad=$ Citra merek

$\mathrm{X}_{4} \quad=$ Kualitas produk

$\mathrm{X}_{5} \quad=$ Harga produk

e $\quad=$ Error term (tingkat kesalahan) (Janie, 2012).

Uji yang digunakan untuk mengetahui apakah terdapat pengaruh secara simultan atau serempak variabel independen terhadap loyalitas konsumen sebagai variabel dependen adalah uji $\mathrm{F}$ dengan hipotesis statistiknya sebagai berikut :

Ho : $\beta 1=0, \beta 2=0, \beta 3=0, \beta 4=0$.

Ha $: \beta 1 \neq 0, \beta 2 \neq 0, \beta 3 \neq 0, \beta 4 \neq 0$.

Ho = kepuasan konsumen, citra merek, kualitas produk dan harga produk tidak mempengaruhi secara serempak loyalitas konsumen Teh Cap Bandulan di Kabupaten Pekalongan.

$\mathrm{Ha}=$ kepuasan konsumen, citra merek, kualitas produk dan harga produk mempengaruhi secara serempak loyalitas konsumen Teh Cap Bandulan di Kabupaten Pekalongan. Sedangkan uji yang digunakan untuk mengetahui apakah terdapat pengaruh secara parsial variabel independen terhadap loyalitas konsumen sebagai variabel dependen adalah uji t dengan hipotesis statistik sebagai berikut :

Ho : $\beta 1=0, \beta 2=0, \beta 3=0, \beta 4=0$.

Ha : $\beta 1 \neq 0, \beta 2 \neq 0, \beta 3 \neq 0, \beta 4 \neq 0$.

Ho = kepuasan konsumen, citra merek, kualitas produk dan harga produk tidak mempengaruhi secara parsial loyalitas konsumen Teh Cap Bandulan di Kabupaten Pekalongan.

$\mathrm{Ha}=$ kepuasan konsumen, citra merek, kualitas produk dan harga produk mempengaruhi secara parsial loyalitas konsumen Teh Cap Bandulan di Kabupaten Pekalongan. 
Piramida loyalitas menggambarkan lima tingkatan loyalitas konsumen terhadap suatu produk yang mana setiap tingkatannya merupakan tantangan bagi perusahaan sekaligus aset yang dapat dimanfaatkan oleh perusahaan. Lima tingkatan tersebut diilustrasikan seperti berikut:

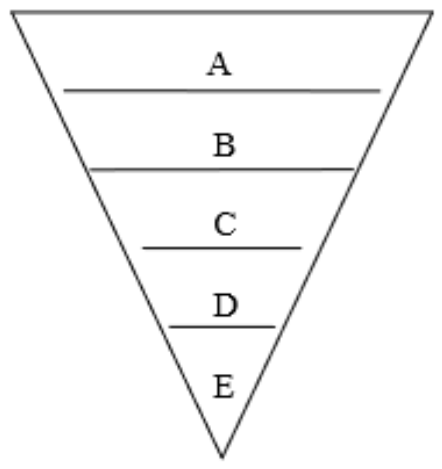

$\mathrm{A}=$ Committed Buyer

$\mathrm{B}=$ Liking the Brand

$\mathrm{C}=$ Satisfied Buyer

$\mathrm{D}=$ Habitual Buyer

$\mathrm{E}=$ Switcher Buyer

Ilustrasi 1. Piramida Loyalitas (Durianto, $d k k .$, 2004).

\section{HASIL DAN PEMBAHASAN}

\section{Gambaran Umum Teh Cap Bandulan}

Teh Cap Bandulan merupakan salah satu produk teh lokal Pekalongan yang diproduksi oleh CV. Budi Djaja yang telah berdiri sejak 1933 dengan produk-produknya yang sudah terkenal dikalangan masyarakat Pekalongan. Pabrik Teh Cap Bandulaan beralamat di Jl. A. Yani No. 10, Noyontaan, Kecamatan Pekalongan Timur, Kota Pekalongan, Kode Pos 51129 sedangkan kantornya berada di wilayah yang sama hanya berjarak beberapa meter saja.

CV. Budi Djaja sendiri bergerak di bidang produksi teh dengan aroma melati. Pemasaran produk Teh Cap Bandulan sudah merambah hampir ke seluruh wilayah di Indonesia namun utamanya adalah Pulau Jawa dan Kalimantan. Beberapa produknya antara lain teh gelas, teh tubruk, teh celup dengan beberapa jenis variasi. Pemilik perusahaan CV. Budi Djaja saat ini adalah Bapak Willyanto yang merupakan ahli waris sekaligus cucu dari Thang Tjeng Kiat dan Nyonya Kho Pek Ngoo yang merupakan perintis bisnis Teh Cap Bandulan. Ciri khas dari Teh Cap Bandulan adalah bunga gambir dan bunga melati (Taufiqurohman, 2019).

\section{Analisis Regresi Linear Berganda}

Analisis data yang dilakukan dalam penelitian ini bertujuan untuk mengetahui pengaruh beberapa faktor terhadap loyalitas konsumen terhadap produk teh cap bandulan di Kabupaten Pekalongan. 
Tabel 1. Hasil Uji Analisis Regresi Linear Berganda

\begin{tabular}{llllll}
\hline \hline No. & Variabel & B & t & F & R Square \\
\hline & Constant & $-3,919$ & $-1,921$ & & \\
1. & Kepuasan Konsumen $\left(\mathrm{X}_{1}\right)$ & 0,555 & 4,630 & 20,163 & 0,465 \\
2. & Citra Merek $\left(\mathrm{X}_{2}\right)$ & 0,370 & 3,172 & 20,163 & 0,465 \\
3. & Kualitas Produk $\left(\mathrm{X}_{3}\right)$ & 0,111 & 0,901 & 20,163 & 0,465 \\
4. & Harga Produk $\left(\mathrm{X}_{4}\right)$ & 0,112 & 1,055 & 20,163 & 0,465 \\
\hline
\end{tabular}

Sumber: Analisis Data Primer, 2020.

Berdasarkan data yang diperoleh pada Tabel 1. dapat dibentuk persamaan uji analisis regresi linear berganda sebagai berikut:

$Y=-3,919+(0,555) X_{1}+(0,370) X_{2}+(0,111) X_{3}+(0,112) X_{4}+e$

Nilai konstanta pada persamaan diatas bernilai negatif yaitu $-3,919$ artinya apabila variabel $\mathrm{X}$ yaitu kepuasan konsumen, citra merek, kualitas produk, dan harga produk memiliki nilai nol menyebabkan tingkat loyalitas konsumen terhadap Teh Cap Bandulan akan menurun, sedangkan nilai masing-masing variabel independen bernilai positif yaitu $X_{1}$ sebesar $0,555, X_{2}$ sebesar $0,370, X_{3}$ sebesar 0,111, $\mathrm{X}_{4}$ sebesar 0,112.

Koefisien $\mathrm{X}_{1}$ bernilai 0,555 memiliki arti bahwa ketika faktor kepuasan konsumen meningkat maka akan terjadi peningkatan loyalitas konsumen sebesar 0,555 . Hal ini juga berlaku pada koefisien $\mathrm{X}_{2}, \mathrm{X}_{3}$, dan $\mathrm{X}_{4}$.

Hasil analisis menunjukkan bahwa nilai koe koefisien determinasi pada penelitian ini berupa nilai $R$-Square sebesa 0,465 atau $46,5 \%$ (Tabel 1.). Nilai tersebut menunjukkan bahwa loyalitas konsumen menjelaskan variasi dari faktor kepuasan konsumen, citra merek, kualitas produk, dan harga produk sebesar 46,5\%. Semakin tinggi nilai koefisien determinasi maka semakin tinggi pula pengaruh variabel-variabel independen terhadap variabel dependen.

Hasil analisis uji $\mathrm{F}$ menunjukkan nilai $\mathrm{F}$ hitung sebesar 20,163 dan nilai signifikansinya 0,000 . Nilai $F$ tabel dalam penelitian ini sendiri adalah sebesar 2,47. Hal ini menunjukkan bahwa nilai $F$ hitung $>$ nilai $F$ tabel, yang artinya terdapat pengaruh dari variabel independen (Y) secara simultan terhadap variabel dependen $(\mathrm{X})$. Sehingga dapat disimpulkan bahwa variabel-variabel independen (X) yang digunakan dalam penelitian ini meliputi kepuasan konsumen, citra merek, kualitas produk, dan harga produk secara simultan mempengaruhi variabel dependen (Y) yaitu loyalitas konsumen terhadap Teh Cap Bandulan di Kabupaten Pekalongan.

Hasil analisis uji t menunjukkan bahwa nilai t hitung variabel kepuasan konsumen $\left(\mathrm{X}_{1}\right)$ sebesar 4,630, variabel citra merek $\left(\mathrm{X}_{2}\right)$ sebesar 3,172, variabel kualitas produk $\left(\mathrm{X}_{3}\right)$ sebesar 0,901 , dan variabel harga produk $\left(\mathrm{X}_{4}\right)$ sebesar 1,055 dengan nilai $t$ tabel sebesar 1,98525. Hal ini menunjukkan bahwa nilai $t$ hitung variabel $\mathrm{X}_{1}$ dan $\mathrm{X}_{2}$ lebih besar daripada nila t tabel artinya bahwa terdapat pengaruh secara parsial dari variabel $X_{1}$ dan $X_{2}$ terhadap variabel $Y$, sedangkan nilai $t$ hitung $X_{3}$ dan $X_{4}$ lebih kecil daripada nilai t tabel artinya bahwa tidak terdapat pengaruh secara parsial dari variabel $\mathrm{X}_{3}$ dan $\mathrm{X}_{4}$ terhadap variabel $\mathrm{Y}$. 
Senada dengan pendapat dari Suharyadi dan Purwanto (2011) yang menyatakan bahwa kaidah penerimaan uji-t apabila nilai t hitung $>t$ tabel artinya terdapat pengaruh secara parsial variabel-variabel $\mathrm{X}$ terhadap variabel $\mathrm{Y}$, sedangkan kaidah penolakan uji-t apabila $t$ hitung $<\mathrm{t}$ tabel artinya tidak terdapat pengaruh secara parsial variabel-variabel X terhadap variabel Y.

Kepuasan konsumen berpengaruh secara parsial terhadap loyalitas konsumen dalam membeli Teh Cap Bandulan dikarenakan konsumen merasakan kepuasan setelah mengonsumsi produk tersebut dan memiliki minat untuk melakukan pembelian ulang yang merupakan salah satu ciri dari loyalitas konsumen. Citra merek juga berpengaruh secara parsial terhadap loyalitas konsumen dikarenakan Teh Cap Bandulan memiliki kesan positif yang melekat dibenak masyarakat sehingga minat beli terhadap produk semakin tinggi. Kualitas produk tidak berpengaruh secara parsial dikarenakan rata-rata konsumen yang tidak terlalu memperhatikan kualitas dari produk. Harga produk juga tidak mempengaruhi loyalitas konsumen secara parsial karena harga Teh Cap Bandulan yang tergolong mudah dijangkau oleh semua kalangan sehingga konsumen tidak mempermasalahkan hal tersebut saat melakukan pembelian ulang.

\section{Piramida Loyalitas}

Piramida loyalitas digunakan untuk memetakan jenis pembeli produk Teh Cap Bandulan di Kabupaten Pekalongan dan mengetahui berapa banyak pembeli produk Teh Cap Bandulan yang merupakan konsumen loyal. Berikut tabel hasil perhitungan setiap tingkatan pada piramida loyalitas :

Tabel 2. Perhitungan Switcher Buyer

Apabila harga produk Teh Cap Bandulan yang Anda konsumsi mengalami kenaikan, apakah Anda akan tetap membeli produk Teh Cap Bandulan?

\begin{tabular}{lllll}
\hline Jawaban & $\mathbf{X}$ & $\mathbf{f}$ & $\mathbf{f . X}$ & $\mathbf{\%}$ \\
Sangat tidak setuju & 1 & 2 & 2 & 0,60 \\
Tidak setuju & 2 & 6 & 12 & 3,57 \\
Ragu-ragu & 3 & 49 & 147 & 43,75 \\
Setuju & 4 & 40 & 160 & 47,62 \\
Sangat Setuju & 5 & 3 & 15 & 4,46 \\
Total & 100 & 336 & $100 \%$ \\
\hline Rata-rata & $\frac{336}{100}=3,36$ \\
& \multicolumn{5}{|c|}{$\frac{(2+6)}{100} \times 100 \%=8 \%$} \\
\hline
\end{tabular}

Sumber: Analisis Data Primer, 2020. 
Tabel 3. Perhitungan Habitual Buyer

Apakah Anda selalu melakukan pembelian produk Teh Cap Bandulan dan tidak pernah membeli produk teh lainnya?

\begin{tabular}{lllll}
\hline Jawaban & $\mathbf{X}$ & $\mathbf{f}$ & $\mathbf{f . X}$ & $\mathbf{\%}$ \\
\hline Sangat tidak setuju & 1 & 10 & 10 & 3,40 \\
Tidak setuju & 2 & 20 & 40 & 13,6 \\
Ragu-ragu & 3 & 38 & 114 & 38,78 \\
Setuju & 4 & 30 & 120 & 40,82 \\
Sangat Setuju & 5 & 2 & 10 & 3,40 \\
Total & 100 & 294 & $100 \%$ \\
\hline Rata-rata & $\frac{294}{100}=2,94$ \\
& \multicolumn{5}{|c|}{$\frac{(30+2)}{100} \times 100 \%=32 \%$} \\
\end{tabular}

Sumber: Analisis Data Primer, 2020.

Tabel 4. Perhitungan Satisfied Buyer

Apakah Anda menemukan kepuasan karena membeli dan mengkonsumsi produk Teh Cap Bandulan?

\begin{tabular}{|c|c|c|c|c|}
\hline Jawaban & $\mathbf{X}$ & $\mathbf{f}$ & f.X & $\%$ \\
\hline Sangat tidak puas & 1 & 1 & 1 & 0,29 \\
\hline Tidak puas & 2 & 12 & 24 & 7,02 \\
\hline Cukup puas & 3 & 39 & 117 & 34,21 \\
\hline Puas & 4 & 40 & 160 & 46,78 \\
\hline Sangat Puas & 5 & 8 & 40 & 11,70 \\
\hline Total & & 100 & 342 & $100 \%$ \\
\hline Rata-rata & & $\frac{342}{100}=$ & & \\
\hline Satisfied Buyer & & $\frac{(40+8)}{100}$ & & \\
\hline
\end{tabular}

Sumber: Analisis Data Primer, 2020.

Tabel 5. Perhitungan Liking the Brand

\begin{tabular}{|c|c|c|c|c|}
\hline \multicolumn{5}{|c|}{ Apakah Anda benar-benar menyukai produk Teh Cap Bandulan? } \\
\hline Jawaban & $\mathbf{X}$ & $\mathbf{f}$ & f.X & $\%$ \\
\hline Sangat tidak suka & 1 & 1 & 1 & 0,28 \\
\hline Tidak suka & 2 & 5 & 10 & 2,75 \\
\hline Biasa saja & 3 & 37 & 111 & 30,58 \\
\hline Suka & 4 & 44 & 176 & 48,48 \\
\hline Sangat Suka & 5 & 13 & 65 & 17,91 \\
\hline Total & & 100 & 363 & $100 \%$ \\
\hline \multirow[t]{2}{*}{ Rata-rata } & & \multicolumn{3}{|c|}{$\underline{363}=363$} \\
\hline & & \multicolumn{3}{|c|}{$\overline{100}=3,63$} \\
\hline \multirow[t]{2}{*}{ Liking the Brand } & & \multicolumn{3}{|c|}{$(44+13)$} \\
\hline & \multicolumn{4}{|c|}{100} \\
\hline
\end{tabular}

Sumber: Analisis Data Primer, 2020. 
Tabel 6. Perhitungan Committed Buyer

Apakah Anda setuju untuk melakukan pembelian ulang terhadap produk Teh Cap Bandulan dan bersedia merekomendasikan atau memperkenalkan produk Teh Cap Bandulan kepada orang lain?

\begin{tabular}{lllll}
\hline Jawaban & $\mathbf{X}$ & $\mathbf{f}$ & $\mathbf{f . X}$ & $\mathbf{\%}$ \\
\hline Sangat tidak setuju & 1 & 1 & 1 & 0,28 \\
Tidak setuju & 2 & 4 & 8 & 2,23 \\
Ragu-ragu & 3 & 41 & 123 & 34,26 \\
Setuju & 4 & 43 & 172 & 47,91 \\
Sangat Setuju & 5 & 11 & 55 & 15,32 \\
Total & 100 & 359 & $100 \%$ \\
\hline Rata-rata & $\frac{359}{100}=3,59$ \\
& \multicolumn{5}{|c|}{$\frac{(43+11)}{100} \times 100 \%=54 \%$} \\
\hline Committed Buyer & \multicolumn{5}{l}{}
\end{tabular}

Sumber: Analisis Data Primer, 2020.

Rata-rata tanggapan responden untuk pertanyaan switcher buyer adalah 3,36 yang artinya mayoritas responden setuju tetap membeli produk Teh Cap Bandulan meski harga produk terjadi kenaikan dan hanya $8 \%$ (Tabel 2.) dari total 100 responden yang merupakan switcher buyer. Rata-rata tanggapan responden untuk pertanyaan habitual buyer adalah 2,94 (Tabel 3.) yang artinya mayoritas responden cukup setuju bahwa mereka selalu membeli produk Teh Cap Bandulan dan hampir tidak pernah membeli produk lain. Rata-rata tanggapan responden untuk pertanyaan satisfied buyer adalah 3,42 (Tabel 4.) yang artinya mayoritas responden setuju bahwa mereka menemukan kepuasan karena membeli dan mengonsumsi Teh Cap Bandulan. Rata-rata tanggapan responden untuk pertanyaan liking the brand adalah 3,63 yang artinya mayoritas responden setuju bahwa mereka membeli produk Teh Cap Bandulan karena mereka benar-benar menyukai produk tersebut dan sebanyak 57\% (Tabel 5.) dari total 100 responden adalang liking the brand dimana persentase ini merupakan persentase tertinggi dari 5 tingkatan yang ada. Rata-rata tanggapan responden untuk pertanyaan committed buyer adalah 3,59 (Tabel 6.) yang artinya mayoritas responden setuju bahwa mereka akan melakukan pembelian ulang terhadap produk dan memperkenalkan produk kepada orang lain.

Piramida loyalitas yang baik adalah berbentuk piramida terbalik dimana nilai committed buyer lebih besar dari nilai switcher buyer (Yulita, dkk., 2014). Berikut merupakan Ilustrasi 2. Piramida Loyalitas berdasarkan data diatas. 


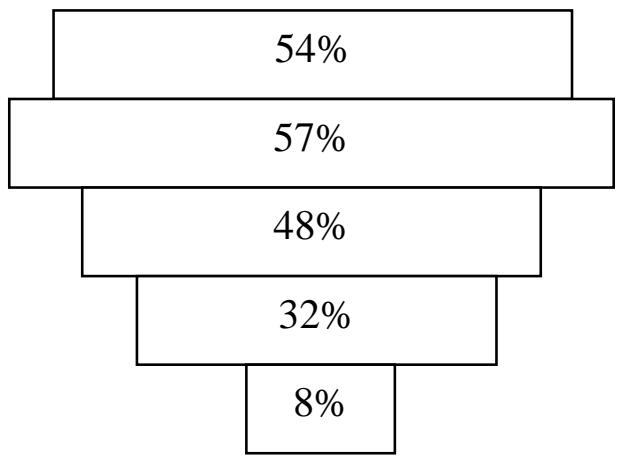

$$
\begin{aligned}
& =\text { committed buyer } \\
& =\text { liking the brand } \\
& =\text { satisfied buyer } \\
& =\text { habitual buyer } \\
& =\text { switcher buyer }
\end{aligned}
$$

Ilustrasi 2. Piramida Loyalitas Konsumen Teh Cap Bandulan di Kabupaten Pekalongan.

\section{KESIMPULAN DAN SARAN \\ Kesimpulan}

1. Loyalitas konsumen Teh Cap Bandulan dipengaruhi secara simultan oleh kepuasan konsumen, citra merek, kualitas produk dan harga produk.

2. Variabel dalam penelitian yang berpengaruh secara parsial terhadap loyalitas konsumen Teh Cap Bandulan adalah kepuasan konsumen dan citra merek sedangkan kualitas produk dan harga produk tidak memberikan pengaruh parsial terhadap loyalitas konsumen Teh Cap Bandulan.

3. Nilai koefisien determinasi dalam penelitian ini senilai $46,5 \%$ yang artinya bahwa faktor kepuasaan konsumen, citra merk, kualitas produk, dan harga produk mempengaruhi loyalitas konsumen Teh Cap Bandulan sebesar 46,5\%.

4. Piramida loyalitas konsumen Teh Cap Bandulan di Kabupaten Pekalongan sudah cukup baik dengan tingkatan loyalitas konsumen Teh Cap Bandulan terbesar dikarenakan faktor kesukaan terhadap merek (liking the brand) yaitu sebesar $57 \%$.

\section{Saran}

Saran yang dapat diberikan kepada perusahaan yaitu mencoba menemukan variasi baru produk Teh Cap Bandulan yang lebih masa kini sehingga dapat menarik semakin banyak remaja untuk membeli Teh Cap Bandulan dan membuat desain baru untuk kemasan Teh Cap Bandulan agar terlihat lebih menarik. Selain itu, memberikan potongan harga pada waktu-waktu tertentu atau mengadakan suatu kegiatan dalam rangka promosi dengan memberikan diskon produk agar dapat menarik perhatian konsumen yang bukan pelanggan Teh Cap Bandulan dan meningkatkan daya saing produk di pasaran. Peningkatan kualitas produk juga dapat dipertimbangan untuk mengelola konsumen Teh Cap Bandulan yang merupakan switcher buyer sehingga apabila sewaktu-waktu terjadi kenaikan harga produk, konsumen tidak keberatan untuk melakukan pembelian ulang dan tidak memilih membeli produk lain. 


\section{DAFTAR PUSTAKA}

Buttle, F. 2004. Customers Relationship Management: Concepts and Tools. Elseveir Butterworth-Heinemann.

Caruana, A. 2002. Service Loyalty: The Effects of Service Quality and the Mediating Role of Customer Satisfaction. European Journal of Marketing. $36(7 / 8): 811-828$.

Dharmmesta, B. S. 1999. Loyalitas pelanggan: sebuah kajian konseptual sebagai panduan bagi peneliti. J. Ekonomi dan Bisnis Indonesia. 14 (3) : 1-25.

Durianto, D., Sugirto dan T. Sitinjak. 2004. Strategi Menaklukkan Pasar Melalui Riset Ekuitas dan Perilaku Merek. PT Gramedia Pustaka Utama, Jakarta.

Etikan, I. dan K. Bala. 2017. Sampling and sampling methods. Biometrics and Biostatistics International Journal. 5 (6) : 00149.

Janie, D. N. A. 2012. Statistik Deskriptif dan Regresi Linier Berganda dengan SPSS. Semarang University Press, Semarang.

Larasati, V. dan R. Suryaputra. 2013. Analisis faktor-faktor yang mempengaruhi loyalitas pelanggan coffe toffe jatim expo di Surabaya. J. GEMA AKTUALITA. 2 (2) : 7-17.

Payadnya, I. P. A. A. dan I. G. A. N. T. Jayantika. 2018. Panduan Penelitian Eksperimen beserta Analisis Statistik dengan SPSS. Deepublish, Yogyakarta.

Somantri R. dan Tanti K. 2013. Kisah dan Khasiat Teh. PT Gramedia Pustaka Utama, Jakarta.

Suharyadi dan Purwanto. 2011. Statistika untuk Ekonomi dan Keuangan Modern. Salemba Empat, Jakarta.

Taufiqurohman, M. 2019. Mereka Mau Hidup Seribu Tahun Lagi: Puluhan Merek Indonesia yang Mampu Bertahan Lebih dari Setengah Abad. Tempo Publishing, Jakarta.

West, R., dan L. H. Turner. Introducing Communication Theory: Analysis and Application. 3rd Edision. McGraw Hill, New York.

Yulita, M., D. A. H. Lestari, dan D. Haryono. 2014. Tingkat kepuasan dan loyalitas konsumen produk susu cair dalam kemasan koperasi peternakan Bandung Selatan (KPBS) di Kota Bandung. J. Ilmu-Ilmu Agribisnis. 2 (2) : 158-165. 